\title{
Estratégias para a política \\ florestal na Amazônia Brasileira - Apresentação
}

De ácordo com o ofício n. ${ }^{\circ} 0130.0034 / 79$, de 15 de julho de 1979 , expedido pelo Dr. Amadeu Cury, Diretor do CNPq, ao Dr. Eneas Salati, Diretor do INPA, que pedia um documento ao INPA, tendo como tema Diretrizes Políticas (em particular a Política Florestal) para o Desenvolvimento da Amazônia (de acordo com o Decreto n. ${ }^{\circ}$ 83.518, de 29.05.79 da Presidência da República), elaboramos um documento que foi encaminhado ao CNPq.

A contribuição do INPA a fim de orientar o Grupo de Trabalho nas suas deliberações e servir de base para a legislação a ser determinada pelo Congresso Nacional é determinada pelas informações científicas disponíveis.

Tendo em vista a deficiência de dados e de informações técnicas e científicas de maneira completa e global qualquer Política Florestal na Amazônia deverá ser implantada com cautela.

Dada a complexidade do assunto, pois que a Política Florestal para uma região como a Amazônia, terá reflexos em todos os aspectos da comunidade, dividimos nossa análise em 06 (seis) sessões, a fim de permitir um estudo analítico do problema a ser enfrentado.

Para efeito desta publicação procedemos modificações e acréscimos. Os trabalhos que no "conteúdo" tiverem um asterisco ao lado do título, foram incluídos posteriormente.

O ponto de vista do INPA foi elaborado, a partir de informações colhidas entre os pesquisadores de maneira geral, e após discutidas foram aqui incorporadas, assim as informações e recomendações incluídas no texto devem ser interpretadas com base no conteúdo dos trabaIhos que compõem este suplemento.

A Comissão de Redação responsável pela montagem do documento enviado ao CNPq e agora editado foi :
- Eneas Salati
Ph. D.
- Pedro Ivo Soares Braga
M.Sc.
- Roberto Figliuolo
M.Sc.

Instituto Nacional de Pesquisas da Amazônia, Manaus - AM 